\title{
Overweight and obesity among Dutch workers: differences between occupational groups and sectors
}

\author{
Karin I. Proper · Vincent H. Hildebrandt
}

Received: 20 November 2008 / Accepted: 26 May 2009 / Published online: 9 June 2009

(C) Springer-Verlag 2009

\begin{abstract}
Purpose To describe the prevalence of overweight and obesity among different occupational groups and sectors in a representative sample of the Dutch working population, and to test whether these differences still exist after adjustment for socio-demographic variables.

Methods Cross-sectional data among 7,588 working adults were used. Univariate analyses of variance was performed to test differences in body mass index (BMI) values between occupational groups $(n=7)$ and sectors $(n=28)$. Adjusted analyses were carried out to examine the role of socio-demographic factors in the differences in overweight and obesity between occupational groups and sectors.

Results On average, the mean BMI was $24.3 \mathrm{~kg} / \mathrm{m}^{2}$ with $31 \%$ being overweight and $6 \%$ being obese. Those working in trade, industrial, or transportation occupations as well as the legislators and senior managers had the highest BMI and a relatively high prevalence of overweight (36.7 and $35.5 \%$, respectively) and obesity (6.9 and $7.5 \%$, respectively). In contrast, those working in scientific and artistic professions had the most favorable BMI profile with $25.7 \%$ being overweight and $4.2 \%$ being obese. After adjusting for sex, age, and education, the proportion of variance changed from about 0.01 to 0.10 with age being the main contributor of the differences in overweight and obesity.

Conclusions BMI profile and prevalence of overweight and obesity differs between occupations and sectors.
\end{abstract}

K. I. Proper $(\square)$

Department of Public and Occupational Health,

EMGO Institute for Health and Care Research,

VU University Medical Center, Amsterdam, The Netherlands

e-mail: KI.Proper@vumc.nl

V. H. Hildebrandt

TNO Quality of Life, Leiden, The Netherlands
Despite the differences are explained partly by socio-demographic factors, based on a given distribution of age, sex, and education within each occupational group and sector, occupational group- and sector-specific strategies to prevent and reduce overweight are recommended.

Keywords Overweight - Obesity · Working population · Prevalence $\cdot$ Occupations $\cdot$ Sectors

\section{Introduction}

In the past few decades, there has been a dramatic increase of overweight and obesity worldwide (Visscher and Seidell 2004; Cameron et al. 2003; Ogden et al. 2006; Joint Health Surveys Unit 2002). Overweight and obesity are commonly measured using the body mass index (BMI), which is calculated by dividing body weight in kilograms by the square of height in meters. Although muscular individuals could mistakenly be placed in the high-risk category, the BMI is a widely accepted and moreover an easy to use and recommended measure for assessing excess body weight in populations. The definitions of overweight (BMI $25.0-29.9 \mathrm{~kg} / \mathrm{m}^{2}$ ) and obesity $\left(B M I \geq 30 \mathrm{~kg} / \mathrm{m}^{2}\right)$ are based on the literature showing an increased risk of morbidity and mortality from several diseases with a BMI above $25 \mathrm{~kg} / \mathrm{m}^{2}$, and especially above $30 \mathrm{~kg} / \mathrm{m}^{2}$ (National Institutes of Health, National Heart Lung, and Blood Institute 1998; WHO 1998). For instance, overweight and obesity are associated with an increased risk of cardiovascular disease, hypertension, type 2 diabetes mellitus, stroke, osteoarthritis, gallbladder disease, and some cancers (Wannamethee et al. 2005; Larsson and Wolk 2007; Flegal et al. 2007; Yang et al. 2009). Next to the public health impact, overweight and obesity have occupational consequences. For example, two recent reviews found 
obesity to be related to higher sick leave, and especially to long term sick leave (Neovius et al. 2009; van Duijvenbode et al. 2009). To illustrate, from a recent prospective study, it appeared that obese employees were more often absent and were absent longer (namely 14 days a year more than normal weight employees), especially when they do not practice sports regularly (Jans et al. 2007a). Further, in another review, Neovius et al. (2008) showed that obesity was significantly associated with disability pension.

Taking into account the negative impact of overweight and obesity on both health and productivity levels, overweight and obesity are associated with an enormous economic burden. For example, Colditz (1999) estimated the direct health care costs due to obesity in the United States to be 70 billion US dollar, representing $7 \%$ of the total health care costs. Studies from other countries, like Canada (Anis et al. 2009), the Netherlands (van Baal et al. 2006), and Switzerland (Schmid et al. 2005) found somewhat lower, but still substantial proportions of the total national health care costs that are attributable to obesity, namely approximately $4 \%$. As to the indirect costs including the value of economic output lost because of illness, injury-related work disability, or premature death, Katzmarzyk and Janssen (2004) estimated the total costs of obesity at Can $\$ 4.3$ billion with the majority of the costs (63\%, Can\$ 2.7 billion) involving indirect costs. Moreover, it was estimated that the obesity-attributable indirect costs represented 3\% of the total indirect costs in Canada in 2001 (Katzmarzyk and Janssen 2004).

With the majority of the adult population in most developed countries being a worker, and many of these workers spending at least $40 \mathrm{~h}$ per week in an occupational setting, the workplace is an important setting for obtaining or promoting a healthy lifestyle. By promoting regular physical activity in combination with a healthy diet, overweight and obesity can be reduced or prevented. Proper and Hildebrandt (2006) showed large differences in physical activity levels (at work and in leisure time) between occupational groups and sectors with workers in the agricultural occupations being the most active, whereas those working in policy and higher executive functions appeared to be the least active. As to the prevalence of overweight and obesity, former studies have demonstrated differences between occupational status groups with a higher prevalence of overweight and obesity among blue collar and shift workers than among white collar and day workers (Nakamura et al. 1997, 2000). Literature on the prevalence of overweight and obesity among different occupational groups (instead of occupational status groups) and sectors, is yet lacking. Such information is, however, relevant to indicate the need of sector-specific strategies for health promotion and for the prevention or treatment of overweight and obesity in particular.

The main aim of this study was therefore to describe the prevalence of overweight and obesity among different occupational groups and sectors in a representative sample of the Dutch working population, and to test differences between the occupational groups and sectors. Moreover, as socio-demographic factors are important determinants of overweight and obesity, the second aim of the present study was to evaluate whether the eventual differences across occupations would still exist after adjustment for such variables.

\section{Methods}

The study population consisted of participants of a continuous, cross-sectional survey ('Injuries and Physical Activity in the Netherlands') over the period from 2000 until 2005. Sampling took place through Random Digit Dialing to obtain a representative sample of the Dutch households. Out of all available phone numbers, a random sample was drawn. The final two digits were deleted automatically, and randomly replaced by two other digits. All phone numbers had thus equal chance to be in the sample. Once a list had been compiled of all the individuals in a given family, the computer selected one of them to act as the respondent. Following this procedure, each year, 10,000 persons were interviewed by telephone using computer-aided telephonic interviewing. For the specific purpose of this study, a selection of the working population was made, including respondents aged 15-64 years working for at least $12 \mathrm{~h}$ per week. Sectors $(n=9)$ with fewer than 100 respondents were excluded from the analyses.

The survey consisted of three parts, namely:

1. a general part to be answered by all respondents, mainly asking about injuries,

2. a part asking a random sample of three quarter of the respondents about their physical activity behavior in general, and

3. a part asking a random sample of one quarter of the respondents about their physical activity behavior in more detail, and the respondents' body weight and height.

Persons with a BMI between 18.5 and $24.9 \mathrm{~kg} / \mathrm{m}^{2}$ were considered to have a healthy weight; those with a BMI between 25.0 and $29.9 \mathrm{~kg} / \mathrm{m}^{2}$ were categorized as overweight; and those with a BMI of $30 \mathrm{~kg} / \mathrm{m}^{2}$ or higher were categorized as obese (National Institutes of Health, National Heart Lung, and Blood Institute 1998; WHO 1998). Participants with underweight $\left(<18.5 \mathrm{~kg} / \mathrm{m}^{2}\right)$ were included with the normal weight group. BMI was calculated from the self-reported body weight and height derived from the third part of the survey filled out by one quarter of the respondents (see above).

All respondents were asked about their occupation as well as the sector, that is the branch of business they were 
working in. Using a coding system of the Statistics Netherlands (CBS), a four-digit code was assigned to each occupation based on the occupation, sector, main activities at work as well as educational and income level. For the purpose of this study, the seven main categories of occupations and 28 sectors distinguished by the CBS were applied.

Data was also collected on the respondent's age, gender, highest level of schooling (on a seven-point scale) and number of hours working.

Data were weighted to family size, education, region, age, and gender to obtain data representative of the general Dutch population. This was done by applying a weighting factor to the entire data file. To calculate mean BMI values and the proportion of workers being overweight and obese per occupational group and sector, descriptive analyses were carried out without any adjustment for certain variables. This was done, because adjusted means would no longer be representative of the specific occupational group or sector, which is just characterized by a given sex-based, age-based and education-based distribution. One-way analyses of variance (ANOVA) were carried out to test differences in BMI between occupational groups and sectors. However, in order to examine the second aim, ANOVA adjusting for the socio-demographic variables sex, age, and education were conducted.

Since weighted data can neither be used in the ANOVA nor in the calculation of confidence intervals, non-weighted data were used. Thereby, the weighted mean could fall outside the non-weighted $95 \%$ confidence interval of the mean.

\section{Results}

The overall non-response due to refusals, language and communication problems was approximately $53 \%$. Over the 6-year period (2000-2005), a total of 60,628 persons were interviewed. Of these, 25,954 met the definition of worker. Of these, 7,720 were presented the third part of the interview including detailed questions as to, among others, body weight and body height. Since there were some missing values on body weight and/or height; complete data of 7,588 workers were available. These were used for the subsequent analyses.

The mean age of the study population $(n=7,588)$ was 38.9 years, $60 \%$ was men, and $38 \%$ had a higher vocational education or university. There were slight differences in the mean age between the occupational groups with the legislators and senior managers having the highest mean age (42.2 years). Moreover, the majority of the workers in this occupational group were men (78\%) and had a higher education (66\%). Two occupational groups were predominantly characterized by a large proportion of men as well as a low proportion of higher educated workers, namely (1)
Table 1 BMI values and proportions of being overweight or obese per age, sex and educational category

\begin{tabular}{|c|c|c|c|c|}
\hline & $N$ & BMI (mean, SD) & Overweight (\%) & Obese $(\%)$ \\
\hline Total & 7,588 & $24.3(3.5)$ & 30.5 & 6.0 \\
\hline \multicolumn{5}{|l|}{ Age } \\
\hline 18-34 year & 2,535 & $23.4(3.2)$ & 22.9 & 3.4 \\
\hline $35-54$ year & 4,043 & $24.8(3.4)$ & 34.9 & 7.0 \\
\hline 55-65 year & 967 & $25.9(3.9)$ & 42.3 & 11.6 \\
\hline \multicolumn{5}{|l|}{ Sex } \\
\hline Men & 4,149 & $24.8(3.3)$ & 35.9 & 6.2 \\
\hline Women & 3,439 & $23.6(3.7)$ & 22.5 & 5.7 \\
\hline \multicolumn{5}{|l|}{ Education } \\
\hline Lower & 1,497 & $25.0(3.8)$ & 34.2 & 9.7 \\
\hline Middle & 2,331 & $24.4(3.5)$ & 30.2 & 6.5 \\
\hline Higher & 2,462 & $24.0(3.2)$ & 28.7 & 3.9 \\
\hline
\end{tabular}

agricultural occupations and (2) trade, industrial, or transportation occupations with 83 and $92 \%$ men, and 10 and 9\% higher educated workers, respectively. In contrast, the majority of service workers appeared to be women (35\% men). As to the sectors, relatively many men were working in the agricultural, horticulture, and fishing sector $(83 \%)$, the metal industry (85\%), the construction industry $(91 \%)$, the transportation sector $(81 \%)$, and the computerization sector $(84 \%)$. The health care and the welfare work sector were both characterized by a high proportion of female workers $(22 \%$ men). The transportation sector was also characterized by a low proportion of higher educated workers $(18 \%)$ as were those working in 'other service functions' $(8 \%)$. In contrast, the education sector had a high proportion of higher educated workers $(82 \%)$ as well as was characterized by a relative high mean age ( 43.7 years).

On average, the BMI of Dutch workers was $24.3 \mathrm{~kg} / \mathrm{m}^{2}$ with $31 \%$ being overweight (BMI $25-29.9 \mathrm{~kg} / \mathrm{m}^{2}$ ) and $6 \%$ being obese (BMI $\geq 30 \mathrm{~kg} / \mathrm{m}^{2}$ ). Higher BMI values were seen at increasing age with mean BMI values of 23.4, 24.8, and $25.9 \mathrm{~kg} / \mathrm{m}^{2}$ for those between the age of $18-34,35-54$, and 55-65 years, respectively (Table 1). A similar trend observed for the prevalence of overweight and obesity with the highest age category having the most unfavorable data (42\% overweight, $12 \%$ obese). Further, women had a lower BMI $\left(23.6 \mathrm{~kg} / \mathrm{m}^{2}\right)$ than men $\left(24.8 \mathrm{~kg} / \mathrm{m}^{2}\right)$, as was true for those with a higher educational level $\left(24.0 \mathrm{~kg} / \mathrm{m}^{2}\right)$ compared to those with a lower education $\left(25.0 \mathrm{~kg} / \mathrm{m}^{2}\right)$. There was a consistent trend in that the lower the educational attainment, the higher the proportion of those being overweight and obese (Table 1).

Persons working in trade, industrial, or transportation occupations as well as the legislators and senior managers had the highest BMI $\left(24.9 \mathrm{~kg} / \mathrm{m}^{2}\right)$ (Table 2). Those in trade, industrial, or transportation occupations had the highest 
Table 2 BMI values and proportions of being overweight or obese per occupational group and sector

\begin{tabular}{|c|c|c|c|c|}
\hline & $N$ & $\begin{array}{l}\text { BMI (mean, SD) } \\
(95 \% \text { CI) }\end{array}$ & Overweight $(\%)$ & Obese $(\%)$ \\
\hline Total & 7,588 & $\begin{array}{l}24.3(3.5) \\
(24.3-24.5)\end{array}$ & 30.5 & 6.0 \\
\hline \multicolumn{5}{|l|}{ Occupational group } \\
\hline Scientific and artistic professions & 2,101 & $\begin{array}{l}23.8(3.5) \\
(23.7-24.1)\end{array}$ & 25.7 & 4.2 \\
\hline Legislators and senior managers & 647 & $\begin{array}{l}24.9(3.1) \\
(24.6-25.1)\end{array}$ & 35.5 & 7.5 \\
\hline Clerks & 1,700 & $\begin{array}{l}24.3(3.4) \\
(24.1-24.5)\end{array}$ & 29.6 & 6.1 \\
\hline Commercial workers & 627 & $\begin{array}{l}24.4(3.7) \\
(24.1-24.8)\end{array}$ & 31.4 & 6.9 \\
\hline Service workers & 784 & $\begin{array}{l}24.1(3.7) \\
(24.0-24.6)\end{array}$ & 27.0 & 7.1 \\
\hline Agricultural occupations & 221 & $\begin{array}{l}24.4(3.4) \\
(24.0-25.0)\end{array}$ & 32.3 & 4.4 \\
\hline Trade, industrial, or transportation occupations & 1,356 & $\begin{array}{l}24.9(3.4) \\
(24.8-25.2)\end{array}$ & 36.7 & 6.9 \\
\hline \multicolumn{5}{|l|}{ Sector } \\
\hline Agriculture, horticulture, fishing & 288 & $\begin{array}{l}24.6(3.3) \\
(24.3-25.1)\end{array}$ & 35.8 & 4.5 \\
\hline Food and stimulants & 134 & $\begin{array}{l}25.1(3.0) \\
(24.5-25.5)\end{array}$ & 44.9 & 4.5 \\
\hline Metal industry & 340 & $\begin{array}{l}24.7(3.3) \\
(24.4-25.1)\end{array}$ & 36.1 & 6.0 \\
\hline Construction industry & 554 & $\begin{array}{l}25.0(3.4) \\
(24.7-25.3)\end{array}$ & 36.0 & 6.5 \\
\hline Retail and wholesale trade & 806 & $\begin{array}{l}24.3(3.6) \\
(24.1-24.6)\end{array}$ & 29.5 & 7.1 \\
\hline Catering industry & 223 & $\begin{array}{l}23.5(3.9) \\
(23.3-24.5)\end{array}$ & 22.3 & 6.8 \\
\hline Transportation & 358 & $\begin{array}{l}25.2(3.7) \\
(24.9-25.7)\end{array}$ & 41.5 & 8.2 \\
\hline Health care & 1,033 & $\begin{array}{l}23.8(3.4) \\
(23.7-24.1)\end{array}$ & 26.1 & 4.6 \\
\hline Education & 541 & $\begin{array}{l}24.0(4.1) \\
(23.7-24.3)\end{array}$ & 27.8 & 4.2 \\
\hline Banking and insurance & 296 & $\begin{array}{l}24.2(3.4) \\
(23.8-24.6)\end{array}$ & 27.6 & 6.8 \\
\hline Computerization & 322 & $\begin{array}{l}24.5(3.2) \\
(24.1-24.8)\end{array}$ & 37.3 & 3.1 \\
\hline Petroleum, rubber, chemical industry & 133 & $\begin{array}{l}24.4(2.9) \\
(23.9-24.9)\end{array}$ & 31.0 & 4.2 \\
\hline Post and telecommunications & 116 & $\begin{array}{l}24.3(3.1) \\
(24.0-25.1)\end{array}$ & 36.1 & 4.8 \\
\hline Welfare work & 252 & $\begin{array}{l}24.1(3.5) \\
(23.8-24.7)\end{array}$ & 25.8 & 7.2 \\
\hline Culture, sport and recreation & 180 & $\begin{array}{l}23.8(3.2) \\
(23.2-24.1)\end{array}$ & 24.0 & 6.1 \\
\hline Government and judicial organization & 547 & $\begin{array}{l}24.2(3.2) \\
(24.0-24.5)\end{array}$ & 28.9 & 4.8 \\
\hline Commercial services & 909 & $\begin{array}{l}24.3(3.6) \\
(24.1-24.6)\end{array}$ & 27.0 & 7.7 \\
\hline Paper, printing, publishing trade & 130 & $\begin{array}{l}24.1(3.7) \\
(23.6-25.0)\end{array}$ & 24.0 & 7.0 \\
\hline Other service functions & 111 & $\begin{array}{l}24.5(3.8) \\
(24.0-25.5)\end{array}$ & 25.6 & 11.3 \\
\hline
\end{tabular}


prevalence of overweight, namely $37 \%$; the legislators and senior managers had the highest prevalence of obesity $(8 \%)$. Those working in scientific and artistic professions had the lowest average BMI value $\left(23.8 \mathrm{~kg} / \mathrm{m}^{2}\right)$ as well as the lowest prevalence of overweight and obesity (overweight $26 \%$, obese $4 \%$ ). Although service workers had a BMI value below average $\left(24.1 \mathrm{~kg} / \mathrm{m}^{2}\right)$ and a relatively low prevalence of those being overweight (27\%), the proportion of those being obese appeared to be relatively high, namely $7 \%$.

There were three sectors with a relatively low BMI value, i.e., (1) the catering industry $\left(23.5 \mathrm{~kg} / \mathrm{m}^{2}\right)$, (2) the health care sector $\left(23.8 \mathrm{~kg} / \mathrm{m}^{2}\right)$, and (3) the culture, sport and recreation sector $\left(23.8 \mathrm{~kg} / \mathrm{m}^{2}\right)$. These sectors also showed relatively low proportions of workers being overweight, namely 22, 26, and 24\%, respectively (Table 2). Those working in the computerization sector showed a low proportion of obese workers (3\%), but a relatively high proportion of those being overweight (37\%). A similar pattern, but the other way round was seen among those working in the paper, printing, and publishing trade showing a relatively low proportion of overweight workers (24\%), but a relatively high prevalence of those being obese (7\%). The transportation sector and the food and stimulants sector showed relatively high BMI values $\left(25.2\right.$ and $25.1 \mathrm{~kg} / \mathrm{m}^{2}$, respectively) and had relatively many overweight workers (42 and $45 \%$, respectively). As to the prevalence of obesity within these two sectors, the food and stimulants sector had a below average proportion, whereas a high proportion of obese workers was apparent within the transportation sector $(8 \%)$. Although neither a high mean BMI was apparent nor a high proportion of overweight workers, the 'other service functions' sector showed by far the highest proportion of obese workers $(11 \%)$ (Table 2).

From the analysis adjusted for socio-demographic variables, it appeared that adjustment resulted in slightly smaller differences in mean BMI values between the occupational groups and sectors (Table 3 ). The proportion of variance explained $\left(R^{2}\right)$ changed substantially; the $R^{2}$ changed from 0.012 and 0.014 (unadjusted) for occupational groups and sectors, respectively to 0.102 and 0.108 , respectively after adjusting for age, sex, and education. Age appeared to be the main contributor followed by sex.

\section{Discussion}

Our findings showed large differences between occupational groups and sectors in the prevalence of overweight and obesity. The proportion of overweight workers varied from 26 to $37 \%$ within the occupational groups, and from 22 to $45 \%$ within the sectors. The proportion of obese workers varied from 4 to $7 \%$, and 3 to $11 \%$, respectively. Although our main purpose was to determine the BMI pro- file among diverse occupational groups and sectors regardless of the influence of age, sex, and education, it seemed that the differences between the occupational groups and sectors were explained partly by variations in these sociodemographic variables. To illustrate, those occupational groups and sectors with a favorable BMI profile had on average a high proportion of higher educated and/or female workers. In contrast, the occupational groups and sectors with a high prevalence of overweight and obesity were generally characterized by relatively many male and lower educated workers. The question that thus arises is: to what extent are differences in BMI between occupational groups and sectors the result of differences in the distribution of variables, like age, sex, and education? To investigate this question, we also conducted analyses taking into account those variables. From the adjusted analyses, it indeed appeared that the socio-demographic factors are responsible for some of the variance in BMI profile between the occupational groups en sectors. The inverse association between educational level, or broader: socio-economic status, and obesity has already been demonstrated in diverse studies (Proper et al. 2007; Qader et al. 2008; Bakhshi et al. 2008). Nevertheless, based on our findings demonstrating differences in the prevalence of overweight and obesity between occupational groups and sectors, an occupationaland sector-specific strategy seems appropriate for weight gain prevention and reduction initiatives.

As said, no studies have been performed that examined differences in BMI values or the prevalence of overweight and obesity between occupational groups or sectors, a few studies did describe the prevalence of overweight and obesity between occupational status groups (e.g., blue collar vs. white collar workers, or skilled workers vs. non-skilled workers). Although different groups were studied, our findings support those findings that demonstrated a higher prevalence of overweight and obesity among blue collar workers than among white collar workers (Nakamura et al. 1997, 2000).

To explain the prevalence of overweight and obesity within the occupational groups, it can be assumed that workers with high levels of physical activity, would have a relatively low prevalence of overweight and obesity, and the other way round. As work is still a major contributor of the total daily physical activity (Proper and Hildebrandt 2006), it was assumed that those working in occupations that require a certain amount of physical activity, would have a low prevalence of overweight and obesity. Next to physical activity, there is increasing evidence for the independent association of sedentary behavior and overweight/ obesity (Proper et al. 2007; Salmon et al. 2000; Brown et al. 2005; Dunstan et al. 2004). From previous studies among a representative sample of the Dutch working population as well, it appears that these assumptions were indeed true for 
Table 3 Results of the unadjusted and adjusted analysis of variance to test differences in BMI between occupational groups and sectors

\begin{tabular}{|c|c|c|c|c|c|}
\hline & $\begin{array}{l}\text { BMI } \\
\text { unadjusted }\end{array}$ & $\begin{array}{l}\text { BMI adjusted } \\
\text { for age }\end{array}$ & $\begin{array}{l}\text { BMI adjusted } \\
\text { for sex }\end{array}$ & $\begin{array}{l}\text { BMI adjusted } \\
\text { for education }\end{array}$ & $\begin{array}{l}\text { BMI adjusted } \\
\text { for age, sex, } \\
\text { and education }\end{array}$ \\
\hline Occupational group $\left(R^{2}\right)$ & 0.012 & 0.078 & 0.033 & 0.017 & 0.102 \\
\hline Scientific and artistic professions & $23.8(0.005)$ & $23.8(0.004)$ & $23.9(0.005)$ & $24.0(0.005)$ & $24.0(0.005)$ \\
\hline Legislators and senior managers & $24.9(0.008)$ & $24.6(0.008)$ & $24.7(0.008)$ & $25.1(0.009)$ & $24.6(0.008)$ \\
\hline Clerks & $24.3(0.005)$ & $24.3(0.005)$ & $24.5(0.005)$ & $24.3(0.006)$ & $24.5(0.005)$ \\
\hline Commercial workers & $24.4(0.008)$ & $24.5(0.008)$ & $24.4(0.008)$ & $24.4(0.009)$ & $24.6(0.008)$ \\
\hline Service workers & $24.1(0.007)$ & $24.2(0.007)$ & $24.4(0.007)$ & $24.0(0.008)$ & $24.4(0.008)$ \\
\hline Agricultural occupations & $24.4(0.013)$ & $24.4(0.013)$ & $24.2(0.013)$ & $24.2(0.014)$ & $24.0(0.014)$ \\
\hline Trade, industrial, or transportation occupations & $24.9(0.005)$ & $25.0(0.005)$ & $24.5(0.006)$ & $24.7(0.005)$ & $24.5(0.006)$ \\
\hline Sector & 0.014 & 0.083 & 0.034 & 0.022 & 0.108 \\
\hline Agriculture, horticulture, fishing & $24.6(0.012)$ & $24.6(0.011)$ & $24.4(0.012)$ & $24.5(0.012)$ & $24.3(0.012)$ \\
\hline Food and stimulants & $25.1(0.017)$ & $25.1(0.017)$ & $25.0(0.017)$ & $25.2(0.019)$ & $25.0(0.018)$ \\
\hline Metal industry & $24.7(0.011)$ & $24.7(0.010)$ & $24.4(0.011)$ & $24.6(0.012)$ & $24.4(0.011)$ \\
\hline Construction industry & $25.0(0.008)$ & $25.1(0.008)$ & $24.6(0.008)$ & $24.9(0.009)$ & $24.8(0.009)$ \\
\hline Retail and wholesale trade & $24.3(0.007)$ & $24.4(0.007)$ & $24.3(0.007)$ & $24.3(0.008)$ & $24.5(0.007)$ \\
\hline Catering industry & $23.5(0.014)$ & $23.9(0.013)$ & $23.7(0.013)$ & $23.3(0.015)$ & $23.9(0.014)$ \\
\hline Transportation & $25.2(0.011)$ & $25.2(0.010)$ & $25.0(0.011)$ & $25.2(0.012)$ & $25.0(0.011)$ \\
\hline Health care & $23.8(0.007)$ & $23.7(0.006)$ & $24.2(0.007)$ & $23.9(0.007)$ & $24.2(0.007)$ \\
\hline Education & $24.0(0.009)$ & $23.6(0.009)$ & $24.2(0.009)$ & $24.1(0.010)$ & $23.8(0.010)$ \\
\hline Banking and insurance & $24.2(0.012)$ & $24.3(0.012)$ & $24.3(0.012)$ & $24.4(0.014)$ & $24.5(0.013)$ \\
\hline Computerization & $24.5(0.011)$ & $24.7(0.011)$ & $24.2(0.011)$ & $24.7(0.013)$ & $24.7(0.012)$ \\
\hline Petroleum, rubber, chemical industry & $24.4(0.017)$ & $24.2(0.017)$ & $24.2(0.017)$ & $24.3(0.019)$ & $24.0(0.018)$ \\
\hline Post and telecommunications & $24.3(0.019)$ & $24.4(0.019)$ & $24.2(0.019)$ & $24.2(0.021)$ & $24.1(0.020)$ \\
\hline Welfare work & $24.1(0.013)$ & $24.0(0.013)$ & $24.5(0.013)$ & $24.1(0.014)$ & $24.4(0.014)$ \\
\hline Culture, sport and recreation & $23.8(0.016)$ & $23.8(0.015)$ & $23.9(0.016)$ & $23.8(0.017)$ & $23.9(0.016)$ \\
\hline Government and judicial organization & $24.2(0.009)$ & $23.9(0.009)$ & $24.1(0.009)$ & $24.3(0.009)$ & $24.0(0.009)$ \\
\hline Commercial services & $24.3(0.007)$ & $24.3(0.007)$ & $24.3(0.007)$ & $24.5(0.007)$ & $24.5(0.007)$ \\
\hline Paper, printing, publishing trade & $24.1(0.018)$ & $24.0(0.018)$ & $24.0(0.018)$ & $24.1(0.020)$ & $24.0(0.019)$ \\
\hline Other service functions & $24.5(0.019)$ & $24.7(0.019)$ & $24.8(0.019)$ & $24.4(0.022)$ & $24.8(0.021)$ \\
\hline
\end{tabular}

Presented are mean (SE) BMI values

some, but nor for all occupational groups. For example, despite their high prevalence of higher educated workers, legislators and senior managers showed a relatively high prevalence of overweight and obesity, and appeared to have low levels of (total daily and occupational) physical activity (Proper and Hildebrandt 2006) and they were sitting significantly longer than the average worker (Jans et al. 2007b). However, looking at those working in scientific and artistic professions with the most favorable BMI profile and lowest prevalence of overweight and obesity, the sitting time nor the (total or occupational) physical activity contribute to their favorable BMI profile. It thereby seems that other factors, such as socio-demographic factors or energy intake are an important contributor as well. As to the role of sociodemographic factors, our findings confirmed the assumption. Regarding energy intake, there is however ample evidence for the important role of diet in the development and reduction of overweight and obesity (Anderson et al. 2001; U.S. Department of Health and Human Services 2001). However, as no studies have been found that investigated the dietary habits among diverse working populations, we can not confirm this assumption. Because of lack of such studies, it is recommended to include (short and valid) questions on the dietary habits in future studies among (worker) populations.

A major strength of the present study was that it included a large, representative sample of the Dutch adult population, in which all occupational groups and sectors were represented. Moreover, as far as the authors are aware of, this study is the first one that describes the prevalence of overweight and obesity among a large and relevant target group for health promotion initiatives (i.e., the working population), and describes differences in the prevalence between the diverse occupational groups and sectors. 
Thereby, this study supplies the knowledge necessary for targeting initiatives as to health promotion to those worker groups which exhibit the highest risks of, for instance, overweight or obesity. Despite the response rate was 53\%, the possibility of selection bias is considered to be low. Namely, as the main focus of the survey was on (all kind of) injuries and physical activity was a second focus, the respondents were not those particularly interested in physical activity, and thus the survey does not include active workers only. Nevertheless, the possibility of selection bias may not be excluded, since it may be that the survey did not reach those workers who were less active, which could have resulted in somewhat lower BMI values.

The most important limitation of this study is that data were self-reported, including body weight and body height. Selfreported BMI has the potential to include social desirability bias, with BMI being underestimated rather than overestimated (Sallis and Saelens 2000; Flood et al. 2000). Using selfreported body weight and body height, there may also be a risk of misclassification when classifying persons as overweight or obese (Flood et al. 2000). This is especially among muscular or athletic persons. They may have a BMI that identifies them as overweight even though they do not have excess body fat. However, we do not think this will have influenced the comparisons between occupations and sectors to a substantial degree. Further, we decided to include persons with underweight (BMI $<18.5 \mathrm{~kg} / \mathrm{m}^{2}$ ) with the normal weight group. Despite it has been shown that persons with a low BMI have an increased mortality rate (Pischon et al. 2008), we expect the impact on the outcomes of this inclusion to be small to very small. Namely, only 148 persons had underweight, which equals $3 \%$ of the number in the normal weight group.

In conclusion, this study showed that there are considerable differences in the prevalence of overweight and obesity between occupational groups and sectors. It further appeared that socio-demographic factors are important underlying determinants of the differences found between occupational groups and sectors. However, as the occupational groups and sectors are characterized by a given sex-, age-, and education-based distribution, the differences in overweight and obesity shown are of relevance and imply a recommendation for an occupational- and sector-specific strategy to prevent (further) weight gain prevention and to reduce overweight and obesity.

Conflict of interest statement The authors declare that they have no conflict of interest.

\section{References}

Anderson JW, Konz EC, Frederich RC, Wood CL (2001) Long-term weight-loss maintenance: a meta-analysis of US studies. Am J Clin Nutr 74:579-584
Anis AH, Zhang W, Bansback N, Guh DP, Amarsi Z, Birmingham CL (2009) Obesity and overweight in Canada: an updated cost-of-illness study. Obes Rev 1 (Epub ahead of print)

Bakhshi E, Eshraghian R, Mohammad K et al (2008) Sociodemographic and smoking associated with obesity in adult women in Iran: results from the National Health Survey. J Public Health 30:429-435

Brown WJ, Williams L, Ford JH, Ball K, Dobson AJ (2005) Identifying the energy cap: magnitude and determinants of five year weight gain in mid-age women. Obes Res 13:1431-1441

Cameron AJ, Welborn TA, Zimmet PZ et al (2003) Overweight and obesity in Australia: the 1999-2000 Australian Diabetes, Obesity and Lifestyle Study (AusDiab). Med J Aust 178:427-432

Colditz GA (1999) Economic costs of obesity and inactivity. Med Sci Sports Exerc 31(Suppl 11):663-667

Dunstan DW, Salmon J, Owen N et al (2004) Physical activity and television viewing in relation to risk of undiagnosed abnormal glucose metabolism in adults. Diabetes Care 27:2603-2609

Flegal KM, Graubard BI, Williamson DF, Gail MH (2007) Cause-specific excess of deaths associated with underweight, overweight, and obesity. JAMA 298:2028-2037

Flood V, Webb K, Lazarus R, Pang G (2000) Use of self-report to monitor overweight and obesity in populations: some issues for consideration. Aust N Z J Public Health 24:96-99

Jans MP, Heuvel van den SG, Hildebrandt VH, Bongers PM (2007a) Overweight and obesity as predictors of absenteeism in the working population of the Netherlands. J Occup Environ Med 49:975980

Jans MP, Proper KI, Hildebrandt VH (2007b) Sedentary behavior in Dutch workers: differences between occupations and business sectors. Am J Prev Med 33:450-454

Joint Health Surveys Unit (on behalf of the Department of Health) (2002) Health Survey for England: cardiovascular disease 1998. The Stationery Office, Norwich

Katzmarzyk PT, Janssen I (2004) The economic costs associated with physical inactivity and obesity in Canada: an update. Can J Appl Physiol 29:90-115

Larsson SC, Wolk A (2007) Overweight, obesity and risk of liver cancer: a meta-analysis of cohort studies. Br J Cancer 97:1005-1008

Nakamura K, Shimai S, Kikuchi S et al (1997) Shift work and risk factors for coronary heart disease in Japanese blue-collar workers: serum lipids and anthropometrical characteristics. Occup Med (Lond) 47:142-146

Nakamura S, Nakamura K, Tanaka M (2000) Increased risk of coronary heart disease in Japanese blue-collar workers. Occup Med (Lond) 50:11-17

National Institutes of Health, National Heart Lung, and Blood Institute (1998). Clinical guidelines on the identification, evaluation, and treatment of overweight and obesity in adults. NIH publication No. 98/4083. http://www.nhlbi.nih.gov/guidelines/obesity/ob_gdlns.pdf

Neovius K, Johansson K, Rössner S, Neovius M (2008) Disability pension, employment and obesity status: a systematic review. Obes Rev 9:572-581

Neovius K, Johansson K, Clark M, Neovius M (2009) Obesity status and sick leave: a systematic review. Obes Rev 10:17-27

Ogden CL, Carroll MD, Curtin LR, McDowell MA, Tabak CJ, Flegal KM (2006) Prevalence of overweight and obesity in the United States, 1999-2004. JAMA 295:1549-1555

Pischon T, Boeing H, Hoffmann K, Bergmann M, Schulze MB, Overvad K et al (2008) General and abdominal adiposity and risk of death in Europe. New Engl J Med 13:2105-2120

Proper KI, Hildebrandt VH (2006) Physical activity among Dutch workers-differences between occupations. Prev Med 43:42-45

Proper KI, Cerin E, Owen N, Brown W (2007) Sitting time and socioeconomic differences in overweight and obesity. Int $\mathrm{J}$ Obes (Lond) 31:169-176 
Qader SS, Shakir YA, Nyberg P, Samsioe G (2008) Sociodemographic risk factors of metabolic syndrome in middle-aged women: results from a population-based study of Swedish women, The Women's Health in the Lund area (WHILA) Study. Climacteric $11: 475-482$

Sallis JF, Saelens BE (2000) Assessment of physical activity by selfreport: status, limitations, and future directions. Res Q Exerc Sport 71:1-14

Salmon J, Bauman A, Crawford D, Timperio A, Owen N (2000) The association between television viewing and overweight among Australian adults participating in varying levels of leisure time physical activity. Int J Obes Relat Metab Disord 24:600-606

Schmid A, Schneider H, Golay A, Keller U (2005) Economic burden of obesity and its comorbidities in Switzerland. Soz Praventivmed 50:87-94

U.S. Department of Health and Human Services (2001) The Surgeon General's call to action to prevent and decrease overweight and obesity. U.S. Department of Health and Human Services, Public Health Service, Office of the Surgeon General, Rockville. www.surgeongeneral.gov/topics/obesity. Accessed 19 Sept 2006 van Baal PHM, Heijnink R, Hoogenveen RT, Polder JJ (2006) Health care costs of unhealthy behavior. Care for euros. RIVM report, Bilthoven

van Duijvenbode DC, Hoozemans MJM, van Poppel MNM, Proper KI (2009) The relationship between overweight \& obesity and sick leave: a systematic review. Int J Obes (in press)

Visscher TLS, Seidell JC (2004) Time trends (1993-1997) and seasonal variation in body mass index and waist circumference in the Netherlands. Int J Obes Relat Metab Disord 28:1309-1316

Wannamethee SG, Shaper AG, Walker M (2005) Overweight and obesity and weight change in middle aged men: impact on cardiovascular disease and diabetes. J Epidemiol Community Health 59:134-139

World Health Organization (1998) Obesity, preventing and managing. The global epidemic. World Health Organization, Geneva

Yang P, Zhou Y, Chen B, et al (2009) Overweight, obesity and gastric cancer risk: results from a meta-analysis of cohort studies. Eur J Cancer 6 (Epub ahead of print) 